\title{
Morphometric evaluation of dural venous sinuses: anatomical study with its implications in surgical interventions
}

\author{
THAMKE, S., KALRA, S.* and KHANDELWAL, A. \\ Department of Anatomy, UCMS and GTB Hospital, Delhi, 110095, India \\ ${ }^{*}$ E-mail: net3laug@yahoo.co.in
}

\begin{abstract}
Introduction: Knowledge of the normal anatomical variations of venous sinuses is important for clinicians and radiologist for investigations and diagnosing various pathologies of dural venous sinuses like thrombosis, embolism and fistula etc. The detailed morphometric study of dural venous sinuses is missing in academic literature. Although few radiological studies have been done in the past but direct anatomical proof in the form of cadaveric study of dural venous sinuses is not available in the literature. Methods: The present study involved the examination of superior sagittal sinus, sigmoid sinus, transverse sinus, straight sinus and occipital sinus in 12 dura maters of formaldehyde fixed cadavers. The length and width (at midpoint and near confluences) of these sinuses and width of confluences were measured with venire callipers. Results: Some remarkable findings were observed in this study. It was established that the width of torcular herophilus is directly proportional to length of superior sagittal sinus and is also directly proportional to length of right sigmoid sinus. Torcular herophilus is situated away from right sigmoid sinus with intervening right transverse sinus and still its width is directly proportional to length of right sigmoid sinus. Also it was observed that the length of straight sinus was directly proportional to length of right transverse sinus. Right sigmoid sinus is a continuation of right transverse sinus but its width increases with increase in width of left transverse sinus. Length of left sigmoid sinus was directly proportional to length of right but width of left sigmoid sinus and vice a versa. Width of left sigmoid sinus is directly proportional to the length of right and left sigmoid sinus. Conclusion: It is extrapolated that this study will be valuable to neurosurgeons for preoperative planning and clinicians and radiologist to prevent misdiagnosis.
\end{abstract}

Keywords: dura mater, dural venous sinuses, crista galli, torcular herophilus, venography.

\section{Introduction}

Dural venous sinuses are a complex of venous channels that lie between the two layers of dura mater, lined by endothelium, have no valves, and their walls are devoid of muscular tissue. They drain blood from the brain and cranial bones (STANDRING, GRAY, ELLIS et al., 2008). Variations in normal patterns were observed in earlier years but the detailed morphometric study of dural venous sinuses is missing in academic literature Detailed study of dural venous sinus is important not only for academic purposes but is also valuable to radiologist, physicians and neurosurgeons for diagnosis of various pathologies and surgical interventions in this region.

The superior sagittal sinus runs in the attached convex margin of the falx cerebri (Figure 1). It begins near the crista galli a few millimetres posterior to the foramen caecum and receives primary tributaries from cortical veins of the frontal lobes, the ascending frontal veins. It is narrow anteriorly, runs backwards show gradual widening to $1 \mathrm{~cm}$. Near the internal occipital protuberance it deviates, usually to the right, and continues as a transverse sinus. Triangular in cross-section, its interior possesses the openings of superior cerebral veins and arachnoid granulations and is traversed by numerous fibrous bands. Its dilated posterior end is the confluence of the sinuses. This is situated usually to the right of the internal occipital protuberance, where the superior sagittal sinus turns to become a right transverse sinus. It also connects with the occipital and contralateral transverse sinus. The size and degree of communication of the channels meeting at the confluence are highly variable. In more than half of subjects all venous channels that converge towards the occiput interconnect, including the straight and occipital sinuses. In many instances communication is absent or tenuous. Any sinus involved may be duplicated, narrowed, or widened near the confluence (STANDRING, GRAY, ELLIS et al., 2008).

The inferior sagittal sinus is positioned in the posterior half or two-thirds of the free margin of the falx cerebri. It increases in size posteriorly, and terminates in the straight sinus (STANDRING, GRAY, ELLIS et al., 2008).

The straight sinus lies in the junction of the falx cerebri with the tentorium cerebella and is also triangular in cross-section. Postero-inferiorly the sinus runs as a continuation of the inferior sagittal sinus into the transverse sinus. The transverse sinuses drain from the confluence of sinuses to the sigmoid sinuses, which ultimately connect to the internal jugular vein. The superior sagittal sinus is usually continuous with right transverse sinus and the straight sinus with the left transverse sinus. On both sides the sinuses run in the attached margin of the tentorium cerebelli. Each follows anterolateral curve, increasing in size and turns down as a sigmoid sinus, which ultimately becomes continuous with the internal jugular vein. Transverse sinuses are triangular in section and usually unequal in size; the one draining the superior sagittal sinus is the larger (STANDRING, GRAY, ELLIS et al., 2008).

The sigmoid sinuses are continuations of the transverse sinuses, beginning where these leave the tentorium cerebella. 


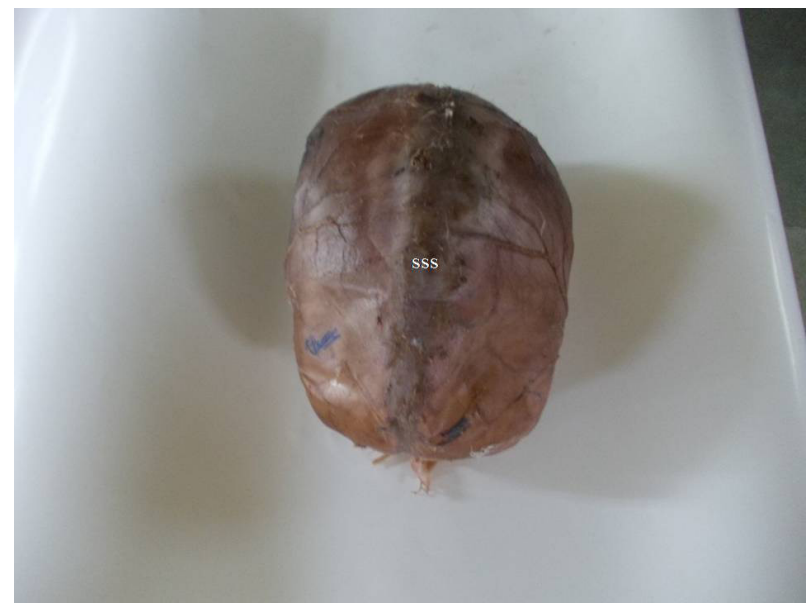

Figure 1. Superior view of the dura mater (meningeal layer) showing superior sagittal sinus (SSS).

Each sigmoid sinus curves inferomedially and turns forward to the superior jugular bulb (STANDRING, GRAY, ELLIS et al., 2008).

The occipital sinus is the smallest of the sinuses, lies in the attached margin of the falx cerebelli and is occasionally paired. It commences near the foramen magnum and ends in the confluence of the sinuses (STANDRING, GRAY, ELLIS et al., 2008).

Cerebral venous sinus thrombosis is a potentially life threatening pathology. Hypercoagulable states, dehydration, adjacent infectious processes, low cerebral blood flow, oral contraceptives, hormone replacement therapy, pregnancy and puerperium augment the risk of cerebral venous sinus thrombosis but exactly why the cerebral venous sinus system is involved over other veins is unclear (CHALOUPKA, MANGLA and HUDDLE, 1999). Quantitative descriptions or morphometric analysis of the dural venous sinus are absent in medical literature. Although few magnetic resonance venography, digital subtraction angiography, conventional spin-echo magnetic resonance imaging, 3D magnetic resonance angiography, microsurgical and histomorphometric studies have been done but we did not find any cadaveric study with quantitative data regarding these in literature search. Knowledge of the normal anatomical variations of venous sinuses prevents misdiagnosis of neurovascular disorders. The configurations of cerebral veins and dural venous sinuses differ not only between individuals but also between the two brain hemispheres of an individual (GÖKÇE, PINARBAŞILI, ACU et al., 2014). Henceforth the purpose of our study is to verify the dimensions and to find out variations of dural venous sinuses.

\section{Materials and Methods}

According to instructions given in Cunningham's dissector, after removal of skull cap a median sagittal incision was given through the endocranium, and superior sagittal sinus was opened (ROMANES, 1986). Its anterior and posterior ends were traced. Incision through the dura mater and endocranium along the whole length of each side of superior sagittal sinus was made. From this incision another one was given to the cut edge of the skull above the auricle. The falx cerebri was exposed by dividing the superior cerebral veins on one side and displacing the upper part of hemisphere laterally. The straight sinus was opened by incising the falx cerebri along left side of its union with the tentorium cerebeli; incision was carried along the free edge of falx cerebri to open the small inferior sagittal sinus. Transverse sinus was opened by continuing the incision laterally in the fixed margin of the tentorium cerebeli from the internal occipital protuberance to base of petrous temporal bone. Continuity of transverse sinus with the sigmoid sinus was noted. On right side superior sagittal sinus draining into transverse sinus and continuity of all sinuses at the internal occipital protuberance were observed (Figure 2). Dura mater was removed carefully from the cribriform plate of the ethmoid. Diaphragma sella was incised radially and hypophysis was dislodged from hypophyseal fossa. The falx cerebelli was slit up and occipital sinus was seen. Sigmoid sinus was opened by passing knife into anterior end of transverse sinus (ROMANES, 1986). Duramater of twelve cadavers fixed with formaldehyde were studied. The dural venous sinuses included in this study are superior sagittal sinus, sigmoid sinus, transverse sinus, straight sinus and occipital sinus. The length and width (at midpoint and near confluences) of these sinuses and width of confluences were measured with venire calliper (Figure 3). As the superior sagittal and sigmoid sinus are curved their length was measured with thread and measuring scale. Measurements were taken by two different observers to eliminate observer bias.

\subsection{Observations}

Length and width of dural venous sinuses were measured. The observations were recorded, tabulated, statistically analysed and correlated by using Pearson correlation, sig (2-tailed) test. The observations are shown in Tables 1-10.

During this study we found out that in one case superior sagittal sinus was draining into left transverse sinus instead of right.

\section{Discussion}

It is well accepted fact that changes in intracranial pressure linked with change in diameter of dural venous sinus (WIDJAJA and GRIFFITHS, 2004). Similarly, it has also been reported that venous sinus anomalies are associated with idiopathic intracranial hypertension (HIGGINS, GILLARD, OWLER et al., 2004), glaucoma (KANTARCI, DANE, GUMUSTEKIN et al., 2005 ) or even intracranial hypotension (BERROIR, GRABLI, HERAN et al., 2004). Also the occlusions of sigmoid sinus in the dominant side or between the two sigmoid sinuses which do not have any patent connection through transverse sinus can trigger venous hypertension (SHEA JUNIOR, 1998). Dural venous sinuses present surgical hazard because they cannot be clamped if opened inadvertently; also, sinuses are related to key structures (i.e, superior petrosal sinus is located immediately superior to sensory root of fifth cranial nerve and sigmoid sinus lies postero-superior to mastoid air cells). Transverse sinus is used for stent placement in the management of patients with Idiopathic intracranial hypertension (AHMEDA, WILKINSON, PARKER et al., 2011).

These observations suggest the further necessitate studying the morphological characteristics and variations of the intracranial sinuses, but there is paucity of literature available hence this study was undertaken to study these venous sinuses 


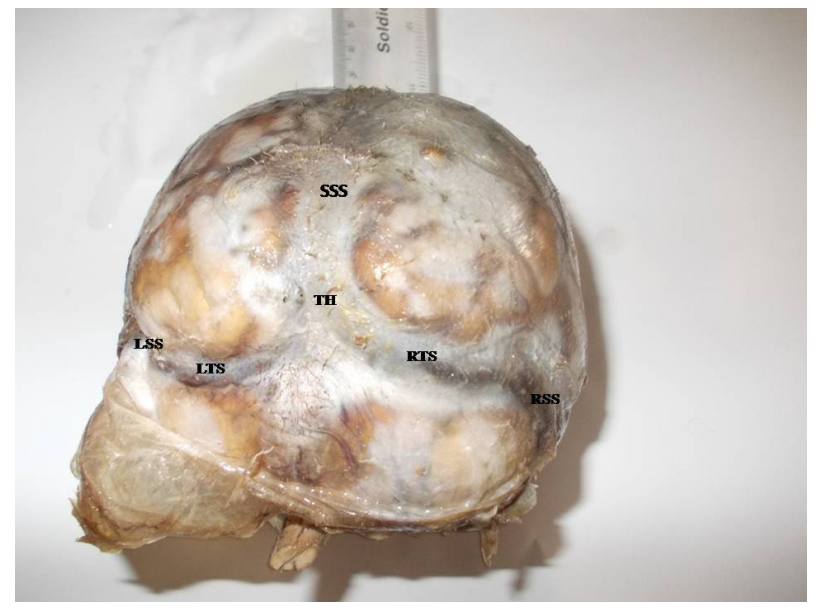

Figure 2. Posterior view of the dura mater (meningeal layer) after removal of cranial vault showing superior sagittal sinus (SSS), torcula herophilus (TH), right transverse sinus (RTS), right sigmoid sinus (RSS), left transverse sinus (LTS), and left sigmoid sinus (LSS).

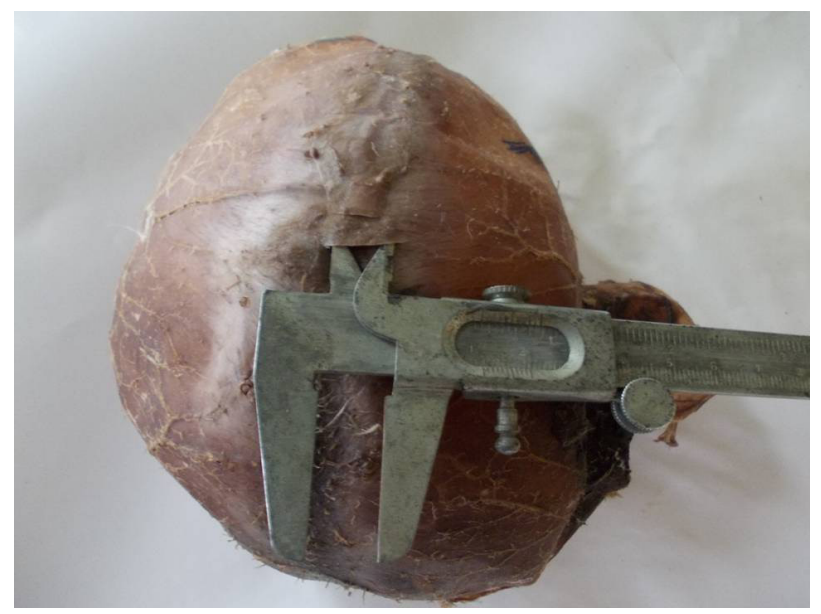

Figure 3. Showing measurement of width of superior sagittal sinus using venire calliper. in the human cadavers. Also, there is no data available for morphometeric features of dural venous sinuses.

Surendrababu, Subathira and Livingstone (2006), using low field magnetic imaging, studied variations in the cerebral venous anatomy and pitfalls in the diagnosis of cerebral venous sinus thrombosis. They noticed hypoplasia of the right transverse sinus in 13 patients, left transverse sinus in 35 patients, right sigmoid sinus in 6 patients and left sigmoid sinus in 19 patients. Absence of transverse sinus on left side was observed in one patient and absence of sigmoid sinus in 2 patients on left side. Flow gaps were observed in non-dominant transverse sinus, sigmoid sinus as well as transverse sigmoid sinus junctions. It was suggested that magnetic resonance angiography done at low field strengths as a reliable method, for assessing cerebral venous sinuses.

Panigrahi, Krishnan and Varma (2012) studied crescent posterior fossa durotomy for occipito-marginal venous sinus preservation. In which opening of the dura as a crescent to avoid damage to the occipital sinus was compared with the standard midline dural opening technique. He found out that this technique preserve the normal venous flow physiology. In quintessence it helps in increased primary dural closures and reduction of pseudomeningiocele/cerebrospinal fluid leak as well as blood loss and venous hypertension.

Luxia (2001) compared 3 dimensional contrast-enhanced magnetization-prepared rapid gradient-echo sequences with 2 dimensional time-of-flight magnetic resonance venography, digital subtraction angiography and conventional spin-echo magnetic resonance imaging for the assessment of normal and abnormal dural sinuses. They reported that three-dimensional contrast-enhanced magnetization-prepared rapid gradient-echo is superior to 2 dimensional time-of-flight magnetic resonance venography and conventional spin-echo magnetic resonance imaging in the depiction of normal venous structures and the diagnosis of dural sinus thrombosis and is a potential alternative to digital subtraction angiography.

Donald, Chakeres, Martha et al. (1990) studied normal venous anatomy with gadopentetate dimeglumine in enhanced 3-D magnetic resonance angiography. They documented good correlation of cut film angiograms and magnetic resonance

Table 1. Mean length of dural venous sinus.

\begin{tabular}{|c|c|c|c|c|c|c|c|}
\hline \multirow{2}{*}{$\frac{\text { DVS }}{\text { LENGTH }}$} & \multirow[t]{2}{*}{$\begin{array}{c}\text { Superior } \\
\text { sagittal sinus }\end{array}$} & \multicolumn{2}{|c|}{$\begin{array}{c}\text { Transverse } \\
\text { sinus }\end{array}$} & \multicolumn{2}{|c|}{$\begin{array}{c}\text { Sigmoid } \\
\text { Sinus }\end{array}$} & \multirow[t]{2}{*}{$\begin{array}{c}\text { Occipital } \\
\text { sinus }\end{array}$} & \multirow[t]{2}{*}{$\begin{array}{c}\text { Straight } \\
\text { sinus }\end{array}$} \\
\hline & & Right & Left & Right & Left & & \\
\hline MEAN & 26.4 & 4.9 & 4.65 & 3.9 & 3.9 & 4.09 & 4.1 \\
\hline SD & 1.68 & 0.77 & 0.73 & 1.04 & 0.96 & 0.78 & 0.37 \\
\hline
\end{tabular}

DVS - Dural venous sinus; SD - Standard Deviation. The mean lengths of right and left sigmoid sinuses were equal and that of occipital and straight sinuses were almost equal.

Table 2. Mean width of dural venous sinus.

\begin{tabular}{|c|c|c|c|c|c|c|c|c|c|}
\hline \multirow{2}{*}{$\frac{\text { DVS }}{\text { Width }}$} & \multicolumn{2}{|c|}{$\begin{array}{c}\text { Superior sagittal } \\
\text { sinus }\end{array}$} & \multicolumn{2}{|c|}{$\begin{array}{c}\text { Transverse } \\
\text { sinus }\end{array}$} & \multicolumn{2}{|c|}{$\begin{array}{l}\text { Sigmoid } \\
\text { sinus }\end{array}$} & \multirow[t]{2}{*}{$\begin{array}{c}\text { Occipital } \\
\text { sinus }\end{array}$} & \multirow[t]{2}{*}{$\begin{array}{c}\text { Straight } \\
\text { sinus }\end{array}$} & \multirow[t]{2}{*}{ Confluences } \\
\hline & Midpoint & $\begin{array}{l}\text { Posterior } \\
\text { end }\end{array}$ & Right & Left & Right & Left & & & \\
\hline Mean & 1.3 & 0.79 & 0.85 & 0.84 & 0.86 & 0.92 & 0.48 & 0.52 & 1.42 \\
\hline SD & 0.26 & 0.15 & 0.24 & 0.3 & 0.2 & 0.21 & 0.06 & 0.21 & 0.38 \\
\hline
\end{tabular}

DVS - Dural venous sinus; SD - Standard Deviation. The mean widths of right and left transverse, and right sigmoid sinuses were almost equal. 
Table 3. Correlation of lengths of right and left sigmoid sinus.

\begin{tabular}{lcc}
\hline & $\begin{array}{c}\text { Mean } \\
\text { length }\end{array}$ & $\begin{array}{c}\text { Standard } \\
\text { Deviation }\end{array}$ \\
\hline $\begin{array}{l}\text { Sigmoid sinus right } \\
\text { Sigmoid sinus left }\end{array}$ & 3.95 & 1.04 \\
Pearson correlation & 3.97 & 0.97 \\
Sig. (2-tailed) & 0.95 \\
Correlation is significant & $0.00(<0.001)$ \\
The mean lengths of left and right sigmoid sinuses were equal and \\
showed positive correlation with p <0.001 which was statistically \\
significant. It means that length of left sigmoid sinus is directly \\
proportional to length of right sigmoid sinus.
\end{tabular}

Table 4. Correlation of lengths of straight sinus and right transverse sinus.

\begin{tabular}{lcc}
\hline & $\begin{array}{c}\text { Mean } \\
\text { length }\end{array}$ & $\begin{array}{c}\text { Standard } \\
\text { Deviation }\end{array}$ \\
\hline $\begin{array}{l}\text { Straight sinus } \\
\text { Transverse sinus right }\end{array}$ & 4.1 & 0.37 \\
Pearson correlation & 4.9 & 0.77 \\
Sig. (2-tailed) & 0.58 \\
Correlation is significant & 0.047 \\
\hline $\begin{array}{l}\text { The mean lengths of straight and right transverse sinuses showed } \\
\text { positive correlation with p <0.05 which was statistically significant. }\end{array}$ \\
It shows that length of straight sinus is increases with increase in \\
length of right transverse sinus.
\end{tabular}

Table 5. Correlation of midpoint width of superior sagittal sinus with left transverse sinus width.

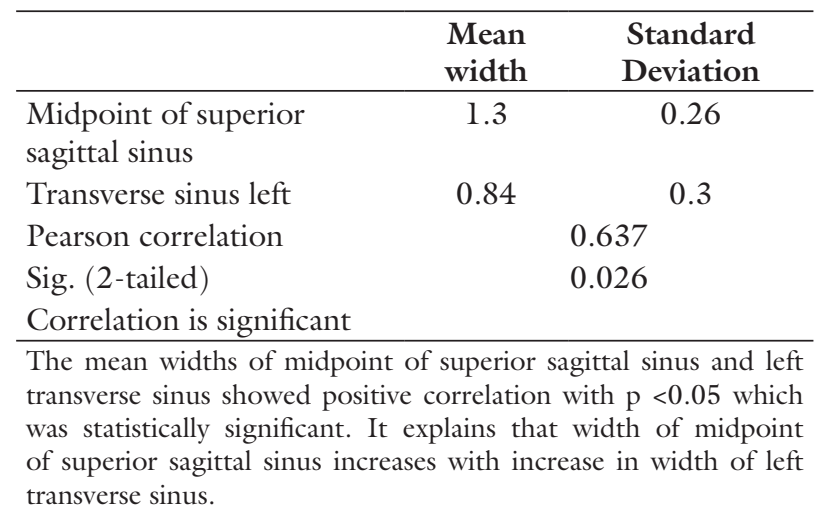

Table 6. Correlation of widths of right sigmoid sinus and left transverse sinus.

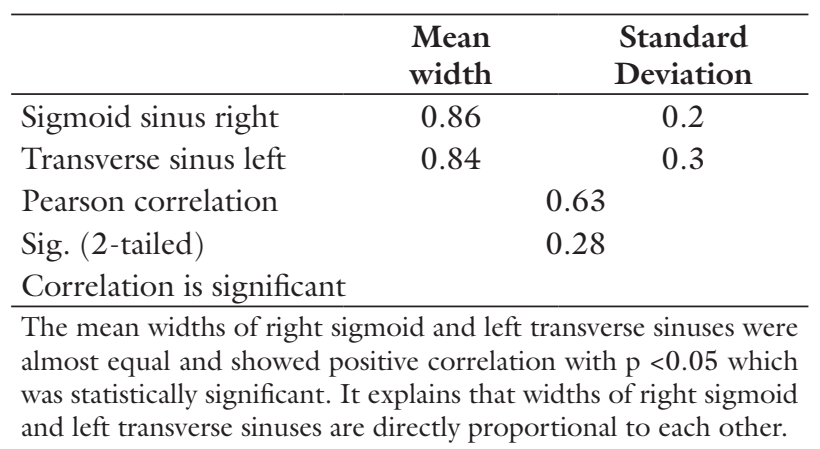

Table 7. Correlation of confluences width with right sigmoid sinus length.

\begin{tabular}{lcc}
\hline & Mean & $\begin{array}{c}\text { Standard } \\
\text { Deviation }\end{array}$ \\
\hline Confluences width & 1.42 & 0.38 \\
Right sigmoid sinus & 3.95 & 1.046 \\
length & 0.597 \\
Pearson correlation & 0.041 \\
Sig. (2-tailed) & \\
Correlation is significant & \\
The mean of confluences width and right sigmoid sinus length \\
showed positive correlation with p <0.05 which was statistically \\
significant. It means that confluences width increases with increase \\
in right sigmoid sinus length.
\end{tabular}

Table 8. Correlation of right sigmoid sinus length with left sigmoid sinus width.

\begin{tabular}{lcc}
\hline & Mean & $\begin{array}{c}\text { Standard } \\
\text { Deviation }\end{array}$ \\
\hline $\begin{array}{l}\text { Right sigmoid } \\
\text { sinus length }\end{array}$ & 3.95 & 1.04 \\
$\begin{array}{l}\text { Left sigmoid sinus } \\
\text { width }\end{array}$ & 0.925 & 0.215 \\
$\begin{array}{l}\text { Pearson } \\
\text { correlation }\end{array}$ & 0.687 \\
$\begin{array}{l}\text { Sig. (2-tailed) } \\
\text { Correlation is significant }\end{array}$ & 0.013 \\
\hline
\end{tabular}

The mean of right sigmoid sinus length and left sigmoid sinus width showed positive correlation with $\mathrm{p}<0.05$ which was statistically significant. It explains that the length of right and width of left sigmoid sinuses are directly proportional to each other.

Table 9. Correlation of width and length of left sigmoid sinus.

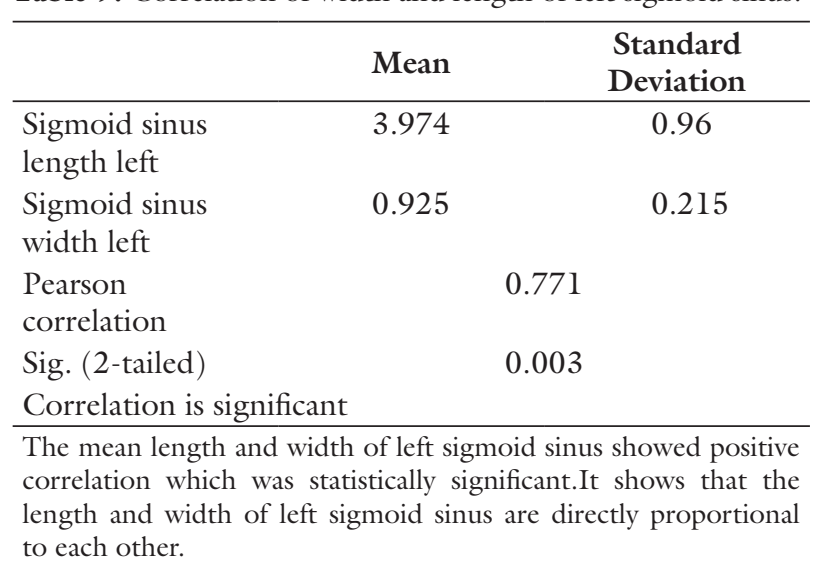

angiograms. Also mentioned that this technique could be used as a venous screening examination and could also substitute for a Tl-weighted enhanced study so that the total examination time would not be seriously lengthened.

Ayanzen, Bird, Keller et al. (2000) observed cerebral magnetic resonance venograms obtained in 100 persons with normal magnetic resonance imaging to determine the presence or absence of the dural sinuses and major intracranial veins. Study concluded with fact that transverse sinus flow gaps can be observed 
Table 10. Correlation of confluences width with superior sagittal sinus length.

\begin{tabular}{lcc}
\hline & Mean & $\begin{array}{c}\text { Standard } \\
\text { Deviation }\end{array}$ \\
\hline Confluences width & 1.42 & 0.38 \\
Superior sagittal sinus & 26.4 & 1.68 \\
length & \multicolumn{2}{c}{-0.676} \\
Pearson correlation & \multicolumn{2}{c}{0.16} \\
Sig. (2-tailed) & \\
Correlation is significant & \\
\hline
\end{tabular}

Confluences width and superior sagittal sinus length showed negative correlation which was statistically significant. It explains that increase in confluences width decreases the length of superior sagittal sinus and vice a versa. During these study we found out that in one case superior sagital sinus was draining into left transverse sinus instead of right.

in as many as $31 \%$ of patients with normal magnetic resonance imaging findings and these gaps should not be mistaken for dural sinus thrombosis. But none of these researchers studied these in human cadavers by direct dissection. Their means of study were indirect radiologic investigations only.

The search of literature found one cadaveric study done is by Deniz (2013) who did mastoidectomy on eight adult male cadavers, total 5 levels of cross-sectional areas were calculated by point counting method. The differences between levels and the sides were evaluated with the Wilcoxon signed-rank test and the relationship was evaluated with spearman's correlation test. Important correlations were found between the anatomical structure and the dimensions of the sinusvein complex to the important landmarks of the temporal bone affecting the appropriate surgical approach to this area. The cross-sectional area of the superior bulb of jugular vein level showed a positive correlation $(\mathrm{p}=0.036)$ with the distance between the Henle spine and the middle fossa dura which is important for mastoidectomy, so when the vein cross-sectional area increases, this distance was also increased. In addition, the distance between the bulb of jugular vein and the round window niche showed negative correlation $(\mathrm{p}=0.013)$ with sectional area of the superior bulb of jugular vein as the area increases, this distance is found to be reduced. The nearest distance between the sigmoid sinuses with the facial nerve was found to be $5.71 \pm$ on the right, $6.03 \pm$ on the left side.

Balak, Ersoy, Uslu et al. (2010) did microsurgical and histomorphometric study of the occipital sinus using stereology. Posterior fossa dura with the superior sagittal sinus, the inferior and superior petrosal sinuses were dissected. The length of the occipital sinuses was measured using callipers. A $0.5-\mathrm{cm}$ section of the occipital sinus was measured for the perimeter and diameter. The sinuses were also examined qualitatively using a surgical microscope. There was no occipital sinus in $6.6 \%$ of total 30 cases. Multiple occipital sinuses were seen in $10 \%$.

In our study we ascertained out that:

1)The width of torcular herophilus is directly proportional to length of superior sagittal sinus. We found one interesting finding that it is also directly proportional to length of right sigmoid sinus. Torcular herophilus is situated away from right sigmoid sinus with intervening right transverse sinus and still its width is directly proportional to length of sigmoid sinus. There was no correlation between dimensions of left sigmoid sinus with torcular herophilus.

2)Superior sagittal sinus usually drains into right transverse sinus but unexpectedly it is seen that midpoint width of superior sagittal sinus increases with width of left transverse sinus.

3)Although straight sinus usually drains into left transverse sinus, interestingly it is found out that the length of straight sinus is directly proportional to length of right transverse sinus.

4)Right sigmoid sinus is a continuation of right transverse sinus but its width increases with width of left transverse sinus

5)Length of left sigmoid sinus increases with increase in length of right and width of left sigmoid sinus and vice a versa.

6)Width of left sigmoid sinus is directly proportional to the length of right and left sigmoid sinus.

7)Length and width of right sigmoid sinus are directly proportional to each other.

8)The dimensions of occipital sinus are independent on any of the above parameters.

\subsection{Embryological basis}

During embryonic development the marginal sinus (should not be mistaken as the marginal sinus at the foramen magnum) from of each side approximated toward the midline to form the superior sagittal sinus. Posteriorly the superior sagittal sinus remain separated into the two limbs which usually join to form the torcular herophili during the sixth fetal month and drain laterally to join the transverse sinus of each side. There may be connecting vascular networks posteriorly between the two limbs of the not however fused superior sagittal sinus, which may produce many variations of the torcular herophili in later life and adjoining dural sinuses. The transverse sinuses enlarge from around the age of 4 months on each side from their lateral border towards medially and reach the torcular herophili. With the increase in size of the telencephalon, the junction of the straight sinus with the superior sagittal sinus gradually descends resulting in the inferior inclination of the lateral part of the transverse sinuses which becomes less marked (OKUDERA, OHTA and HUANG, 1984). The transverse sinuses enlarge and regain a relatively even calibre in the sixth month of intrauterine life. During the period of transition from the stage of plexiform networks to the rapid increase and then decreased in calibre, the torcular and of the lateral sinus may in some cases become irregular. The lateral sinus may be markedly hypoplastic or may even be absent. Unequal heights, asymmetrical sizes, mild to marked irregularities, or even absence of the medial portion of the transverse sinuses are therefore frequently encountered (OKUDERA, OHTA and HUANG, 1984). Less commonly, the lateral portion of the transverse or sigmoid sinus may also be hypoplastic or absent.

The occipital sinus originates from fine plexiform vascular channels originating from the primitive torcular plexus during the third gestational month (OKUDERA, HUANG and OHTA et al., 1994). The occipital sinuses rapidly increase in calibre at the age of 4 to 5 gestational months. Five to 
seven venous channels, originate from the primitive torcular area as well as from the medial portion of both transverse sinuses. They stream toward the already markedly developed prominent marginal sinus around the foramen magnum. In the third gestational month, the primitive internal cerebral vein receives the large superior choroidal vein. The medial cerebral vein drains the anteromedial portion of the primitive cerebral hemisphere and runs backward to open into the anterior portion of the internal cerebral vein of the same side. The two internal cerebral veins unite to form the great cerebral vein of Galen. The internal cerebral vein, vein of Galen, and straight sinus take a relatively straight course at the third gestational month (YOKOTA, OOTA, MATSUKADO et al., 1978). As the cerebral hemispheres enlarge, the straight sinus is displaced and flattened downward and its calibre increases in the sixth gestational month, and the course of the straight sinus declines with descent of the torcular portion (YOKOTA, OOTA, MATSUKADO et al., 1978).

\section{Conclusion}

Knowledge of the anatomy of venous sinuses is important for intracranial surgery as any injury may lead to excessive bleeding. Detailed knowledge of the normal and variant anatomy of dural venous sinuses will be valuable to neurosurgeons during venography, shunt surgeries etc. Variation of dural venous sinuses are also important for clinicians and radiologist for investigations and diagnosing various pathologies of dural venous sinuses like thrombosis, embolism and fistula etc. we hope this study will be useful to neurosurgeons for preoperative planning and clinicians and radiologist to prevent misdiagnosis. In our study we have measured the superior sagittal sinus length from crista galli to confluence of sinuses which roughly corresponds to the external cranial length used for measuring cranial index which is used anthropologically to identify racial differences, therefore the above Indian data of superior sagittal sinus length can be further used to study the racial differences.

\section{References}

AHMEDA, RM., WILKINSON, M., PARKER, GD., THURTELL, MJ. and MACDONALD, J. Transverse sinus stenting idiopathic intracranial hypertension: a review of 52 patients and of model predictions. American Journal of Neuroradiology, 2011, vol. 32, n. 8, p. 1408-1414. http://dx.doi.org/10.3174/ajnr.A2575. PMid:21799038.

AYANZEN, RH., BIRD, CR., KELLER, PJ., MCCULLY, FJ., THEOBALD, MR. and HEISERMAN, JE. Cerebral MR venography. normal anatomy and potential diagnostic pitfalls. American Journal of Neuroradiology, 2000, vol. 21, n. 1, p. 74-78. PMid:10669228.

BALAK, N., ERSOY, G., USLU, U., TANRIÖVER, N., TAPUL, L., CETIN, G., IŞIK, N. and ELMACI, I. Microsurgical and histomorphometric study of the occipital sinus: quantitative measurements using a novel approach of stereology. Clinical Anatomy, 2010, vol. 23 , n. 4 , p. 386-393. http://dx.doi.org/10.1002/ ca.20947. PMid:20196130.

BERROIR, S., GRABLI, D., HERAN, F., BAKOUCHE, P. and BOUSSER, MG. Cerebral sinus venous thrombosis in two patients with spontaneous intracranial hypotension. Cerebrovascular Diseases, 2004, vol. 17, n. 1, p. 9-12. http://dx.doi.org/10.1159/000073892. PMid:14530632.
CHALOUPKA, JC., MANGLA, S. and HUDDLE, DC. Use of mechanical thrombolysis via microballoon percutaneous transluminal angioplasty for the treatment of acute dural sinus thrombosis: case presentation and technical report. Neurosurgery, 1999, vol. 45, n. 3, p. 650-656, discussion 656-657. http://dx.doi.org/10.1097/00006123199909000-00045. PMid:10493388.

DENIZ, U. Evaluation of cross-sectional areas of the sigmoid sinus, jugular bulb and internal jugular vein: a cadaver study. Journal of International Advanced Otology, 2013, vol. 9, n. 2, p. 240-248.

DONALD, W., CHAKERES, PS., MARTHA, B. and CHUN, Y. Normal venous anatomy of the brain. demonstration with gadopentetate dimeglumine in enhanced 3-D MR angiography. American Journal of Neuroradiology, 1990, vol. 11, p. 1107-1118.

GÖKÇE, E., PINARBAȘILI, T., ACU, B., FIRAT, MM. and ERKORKMAZ, Ü. Torcular Herophili classification and evaluation of dural venous sinus variations using digital subtraction angiography and magnetic resonance venographies. Surgical and Radiologic Anatomy, 2014, vol. 36, n. 6, p. 527-536. http://dx.doi.org/10.1007/ s00276-013-1223-0. PMid:24154635.

HIGGINS, JN., GILLARD, JH., OWLER, BK., HARKNESS, K. and PICKARD, JD. MR venography in idiopathic intracranial hypertension unappreciated and is understood. Journal of Neurology, Neurosurgery, and Psychiatry, 2004, vol. 75, n. 4, p. 621-625. http://dx.doi.org/10.1136/jnnp.2003.021006. PMid:15026510.

KANTARCI, M., DANE, S., GUMUSTEKIN, K., ONBAS, O., ALPER, F., OKUR, A., ASLANKURT, M. and YAZICI, AT. Relation between intraocular pressure and size of transverse sinuses. Neuroradiology, 2005, vol. 47, n. 1, p. 46-50. PMid:15647949.

LUXIA, L. Evaluation of the intracranial dural sinuses with a $3 \mathrm{D}$ contrast-enhanced MP-RAGE sequence: prospective comparison with $2 \mathrm{D}$-TOF MR venography and digital subtraction angiography. American Journal of Neuroradiology, 2001, vol. 22, n. 3, p. 481492. PMid:11237970.

OKUDERA, T., HUANG, YP., OHTA, T., YOKOTA, A., NAKAMURA, Y., MAEHARA, F., UTSUNOMIYA, H., UEMURA, $\mathrm{K}$. and FUKASAWA, H. Development of posterior fossa dural sinuses, emissary veins and jugular bulb. Morphological and radiologic study. American Journal of Neuroradiology, 1994, vol. 15, n. 10, p. 1871-1883. PMid:7863937.

OKUDERA, T., OHTA, T. and HUANG, YP. Embryology of the cranial venous system. In KNAPP, JP. and SCHMIDECK, HH. The cerebral penous system and its disorders. Orlando: Grune and Stratton, 1984. p. 93-108.

PANIGRAHI, M., KRISHNAN, SS. and VARMA, DR. Crescent posterior fossa durotomy for occipitomarginal venous sinus preservation: a pilot study. Acta Neurochirurgica, 2012, vol. 154, n. 11, p. 2115-2121. http://dx.doi.org/10.1007/s00701-0121457-3. PMid:22855072.

ROMANES, GJ. Cunningham's manual of practical anatomy: head neck brain, the cranial cavity. 15th ed. Oxford: Oxford Medical Publications, 1986. p. 44-62. vol. 3.

SHEA JUNIOR, JJ. Forty years of stapes surgery. The American Journal of Otology, 1998, vol. 19, n. 1, p. 52-55. PMid:9455948.

STANDRING, S., GRAY, H., ELLIS, H. and BERKOVITZ, BKB. Gray's anatomy: the anatomical basis of clinical practice. 39th ed. Edinburgh: Elsevier Churchill Livingstone, 2008. p. 277-279.

SURENDRABABU, N., SUBATHIRA. and LIVINGSTONE, RS. Variations in the cerebral venous anatomy and pitfalls in the diagnosis of cerebral venous sinus thrombosis: low field MR experience. Indian Journal of Medical Sciences, 2006, vol. 60, n. 4, p. 135-142. http://dx.doi.org/10.4103/0019-5359.24677. PMid:16679629. 
WIDJAJA, E. and GRIFFITHS, PD. Intracranial MR venography in children: normal anatomy and variations. American Journal of Neuroradiology, 2004, vol. 25, n. 9, p. 1557-1562. PMid:15502138.

YOKOTA, A., OOTA, T., MATSUKADO, Y. and OKUDERA, T. Structures and development of the venous system in congenital malformations of the brain. Neuroradiology, 1978, vol. 16, n. 1, p. 26-30. http://dx.doi.org/10.1007/BF00395194. PMid:740187.

Received June 25, 2015

Accepted July 7, 2016 